\title{
Characterization of airborne wear debris produced by brake pads pressed against HVOF-coated discs
}

\author{
C. MENAPACE ${ }^{1, *}$, A. MANCINI ${ }^{2}$, M. FEDERICI ${ }^{1}$, G. STRAFFELINI $^{1}$, S. GIALANELLA ${ }^{1}$ \\ ${ }^{1}$ Department of Industrial Engineering, University of Trento, Trento 38123, Italy \\ ${ }^{2}$ Brembo S.p.A., Bergamo 24040, Italy
}

Received: 27 October 2018 / Revised: 15 December 2018 / Accepted: 22 February 2019

(C) The author(s) 2019.

\begin{abstract}
A significant fraction of the non-exhaust particulate matter emissions from vehicular traffic comprises fine particles from the wear debris of brake pads and discs. Recent studies have shown that these emissions can be consistently reduced by using wear resistant disc coatings. This study thoroughly analyses the debris produced by a low-met brake pad, which is dyno-bench tested against both cast iron and WC-CoCr-coated brake discs. To achieve this, particles in the size range of $2.5 \mu \mathrm{m}$ to $30 \mathrm{~nm}$ were collected and characterized. The results showed a consistent reduction in the particle emission as well as in the concentration of iron oxides, which are mainly released from the disc tribo-oxidation in the coated disc. Furthermore, a few tungsten carbides, released from the coating, were also observed in the wear fragments. The results of this study can be useful for improving the protective coating and consequently help in reducing particulate matter emission further.
\end{abstract}

Keywords: wear debris characterization; wear disc; WC-Co coating; High velocity oxygen fuel (HVOF)

\section{Introduction}

The braking action of a road vehicle causes a frictional torque between the brake pads and brake discs, which slows down the rotational motion of the wheels and finally stops the vehicle. However, both pads and discs are subjected to wear in the process, producing wear fragments of different sizes and mass. A significant fraction (approximately 35\%-50\%) of the wear debris becomes airborne particulate matter (PM) $[1,2]$.

The contribution of the brake wear debris to $\mathrm{PM}_{10}$ and $\mathrm{PM}_{2.5}$ (i.e., $\mathrm{PM}$ with an average aerodynamic diameter smaller than $10 \mu \mathrm{m}$ and $2.5 \mu \mathrm{m}$, respectively) currently represents a consistent part of the total emissions from road transportation [1, 2], despite the major reductions in the exhaust emissions introduced by more efficient engines and retrofitting solutions. The emitted wear debris contains several components, which are potentially hazardous to human health and environmental conditions; and the composition of the emissions depends on that of the pad and disc materials. Therefore, there are ongoing research efforts dedicated to the development of new materials for fabricating brake pads and discs that can achieve a combination of enhanced performance as well as environmental friendliness. However, pad materials are complex composite systems and hence, several strategies are being adopted, starting from the reduction and elimination of critical elements, such as copper [3], to processing routes and microstructural improvement of the standard ingredients [4]. Cast iron is typically used to fabricate vehicular brake discs; and the oxide particles produced by their tribo-oxidation, usually constitute more than $50 \mathrm{wt} \%$ of the total PM emitted from the brake system [5-9]. Therefore, several strategies have been pursued to reduce the wear in the

* Corresponding author: C. MENAPACE, E-mail: cinzia.menapace@unitn.it 
brake discs as well as improve the break performance. One such approach involves the tuning of the chemical composition of cast iron to increase its wear resistance [10]. Furthermore, techniques such as thermochemical treatment of the disc surface [11], plane thermal treatments, either confined to a surface layer or extended to the entire disc thickness [12], and depositing a hard coating on the disc surface [13] have been adopted over years as alternative solutions. Among these, coating is regarded as a promising technique for lowering the total amount of emissions [11]. Stable frictional properties were measured at both low and high temperatures [13]. However, in view of the environmental and human health implications of the wear particle emissions, investigating the phase and chemical composition of the PMs is essential; moreover, it is also important to analyze the distribution of different particle size ranges. Several studies have investigated the size distribution, composition, and relative concentration of the wear debris produced by cast iron discs [1, 5, 14-17], while limited literature is available on particle emission from coated brake discs. Therefore, the main aim of this study is to characterize wear debris produced by commercial low-met brake pads; this is bench-tested against both conventional cast iron and WC-CoCr coated discs. Furthermore, an assessment of the major differences in the chemical composition and microstructural features of the emitted particles is essential to establish the actual improvement affected by the coated discs.

\section{Experimental details}

A commercial brake pad frictional material (codenamed FM4) has been selected to test the braking performance and wear behavior of the coated and uncoated discs.

Two different rotors have been used as discs: an uncoated cast iron disc (codenamed BD1) and the same disc material coated with a WC-CoCr layer (codenamed BD2). The pad material, FM4, has been characterized using X-Ray diffraction (XRD), and a full pattern fitting procedure, based on the Rietveld method [18, 19], for the identification of the main phases and their quantification. The relevant results are listed in Table 1. The SEM micrograph in Fig. 1 shows the microstructure of the pad material, with the indication of the main constituents, as identified
Table 1 Phase composition of the FM4 pad material, as evaluated from XRD data (see main text for details on the experimental method). The concentrations of phenolic resin and of the other organic components are not included. Typical contributions of these components sum up to $7 \mathrm{wt} \%-10 \mathrm{wt} \%$.

\begin{tabular}{cc}
\hline Constituent & Phase wt\% \\
\hline Graphite $(\mathrm{C})$ & 28.8 \\
Corundum $\left(\mathrm{Al}_{2} \mathrm{O}_{3}\right)$ & 15.3 \\
Flogopite $\left(\mathrm{KMg}_{3}\left(\mathrm{Si}_{3} \mathrm{Al}\right) \mathrm{O}_{10}(\mathrm{~F}, \mathrm{OH})_{2}\right)$ & 23.5 \\
$\gamma$-Iron $(\mathrm{Fe})$ & 4.4 \\
Copper $(\mathrm{Cu})$ & 4.0 \\
Anatase $\left(\mathrm{TiO}_{2}\right)$ & 6.2 \\
Zinc $(\mathrm{Zn}))$ & 2.2 \\
$\alpha$-Iron $(\mathrm{Fe})$ & 7.3 \\
Kaolinite $\left(\mathrm{Al} 2 \mathrm{Si} \mathrm{O}_{5}(\mathrm{OH})_{4}\right)$ & 2.2 \\
Chromite $\left(\mathrm{FeCr}_{2} \mathrm{O}_{4}\right)$ & 1.8 \\
Rutile $\left(\mathrm{TiO}_{2}\right)$ & 2.7 \\
Periclase $(\mathrm{MgO})$ & 0.2 \\
Nickel sulfide $\left(N i S_{2}\right)$ & 0.2 \\
Tin sulfide $\left(\mathrm{SnS}_{3}\right.$ & 1.3 \\
\hline
\end{tabular}

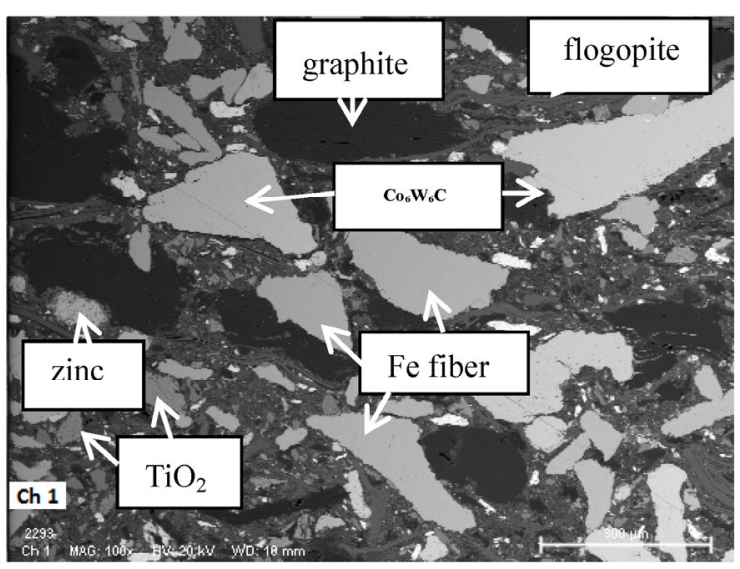

Fig. 1 SEM micrographs showing the microstructure of the FM4 pad material.

from the energy dispersive X-ray spectroscopy (EDXS) data. Metallic ( $\mathrm{Cu}$ and $\mathrm{Fe}$ ) fibers and graphite particles are observed to be the main, coarser components of the pad, while finer particles of corundum and flogopite mica grains are homogeneously distributed into the organic binder, which is a phenolic resin.

The main characteristics of the two disc materials are listed in Table 2. While BD1 is made of a lamellar grey cast iron, $\mathrm{BD} 2$ is made of the same material with a high velocity oxygen fuel (HVOF)-coated layer of a WC-CoCr composite system, of $70 \mu \mathrm{m}$ thickness. The deposition parameters of HVOF have been presented 
Table 2 Main characteristics of BD1 and BD2 discs analyzed in the present investigation.

\begin{tabular}{ccc}
\hline Disc & Material & $\begin{array}{c}\text { Surface } \\
\text { hardness }\end{array}$ \\
\hline BD1 & Pearlitic lamellar grey cast iron & $210 \mathrm{HB}$ \\
BD2 & $(86 \% \mathrm{WC} / 14 \%$ CoCr $)$ coated BD1 disc & $1130 \mathrm{HV} 0.3$ \\
\hline
\end{tabular}

and discussed in our previous paper [13]. Figure 2(a) shows the lamellar cast iron (substrate) and the coating, and Fig. 2(b) shows the higher magnification image of the coating. The tungsten carbides are clearly visible: they appear as brighter sub-micrometric polygonal particles in the figure. Before the wear tests, the coated discs were mechanically polished to an average surface roughness, $R a$, of $1.5 \mu \mathrm{m}$, which is the same as that of the uncoated disc. The XRD analysis of the WC-CoCr coating revealed the presence of about $40 \mathrm{wt} \%$ of $\mathrm{W}_{2} \mathrm{C}$, in addition to the majority $(\sim 60 \mathrm{wt} \%)$ WC phase (Fig. 3(a)). This additional carbide phase, $\mathrm{W}_{2} \mathrm{C}$, is formed as a consequence of the decar- burization of WC, which was initially present in the powder (Fig. 3(b)), during the thermal spraying. This is a-common phenomenon for this deposition technique, especially in the case of heterogeneous powder melting and localized superheating at the surface of the WC particles, owing to the high specific surface area featuring the feedstock powder during the HVOF spraying process [20]. Furthermore, decarburization is also caused by the oxidizing atmosphere and high cooling rates [20,21]. In the XRD pattern of the coated disc, there are no visible cobalt diffraction lines, notwithstanding the fact that $14 \mathrm{wt} \%$ of this metallic component was initially present in the alloy (i.e., $10 \mathrm{wt} \%$ $\mathrm{Co}+4 \mathrm{wt} \% \mathrm{Cr}$ ). This can be explained in terms of the nanocrystallization of cobalt, following its deposition onto the cast iron disc, owing to the rapid solidification and subsequent cooling to room temperature. Therefore, although a Co-Cr solid solution is still present in the coating, it is difficult to be detected using XRD owing to the diffraction-line broadening.
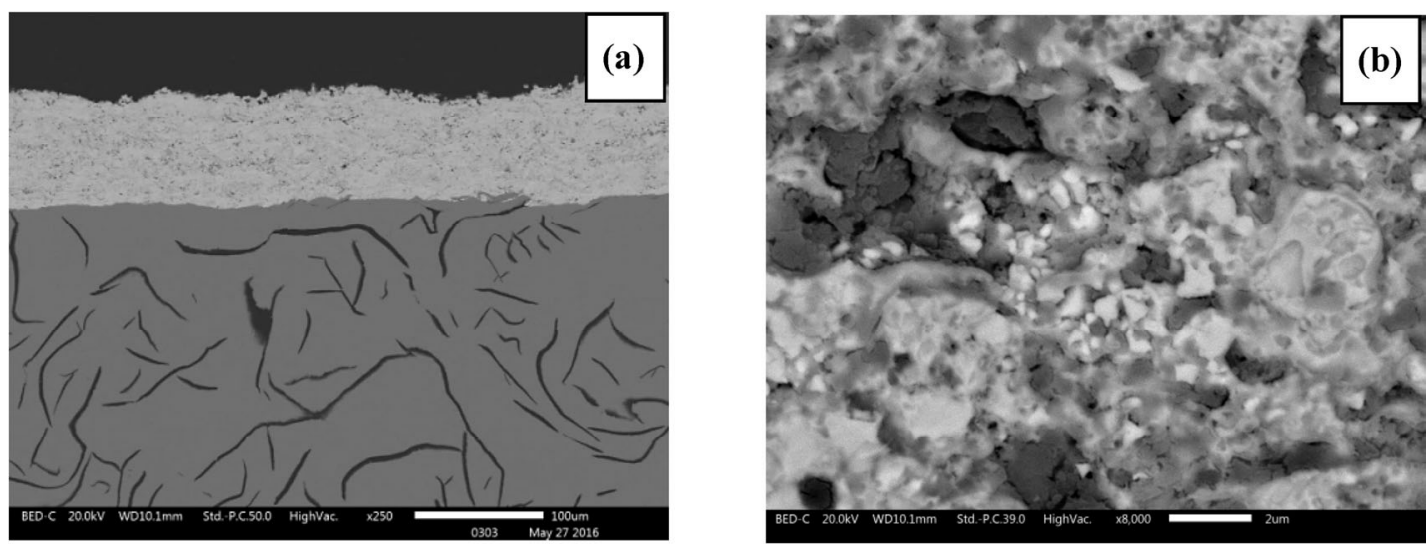

Fig. 2 SEM micrographs showing the cross-section of the BD2 disc at two different magnifications:(a) general view of the WC-CoCr coating, (b) microstructure of the coating. The brighter particles are the tungsten carbide grains.
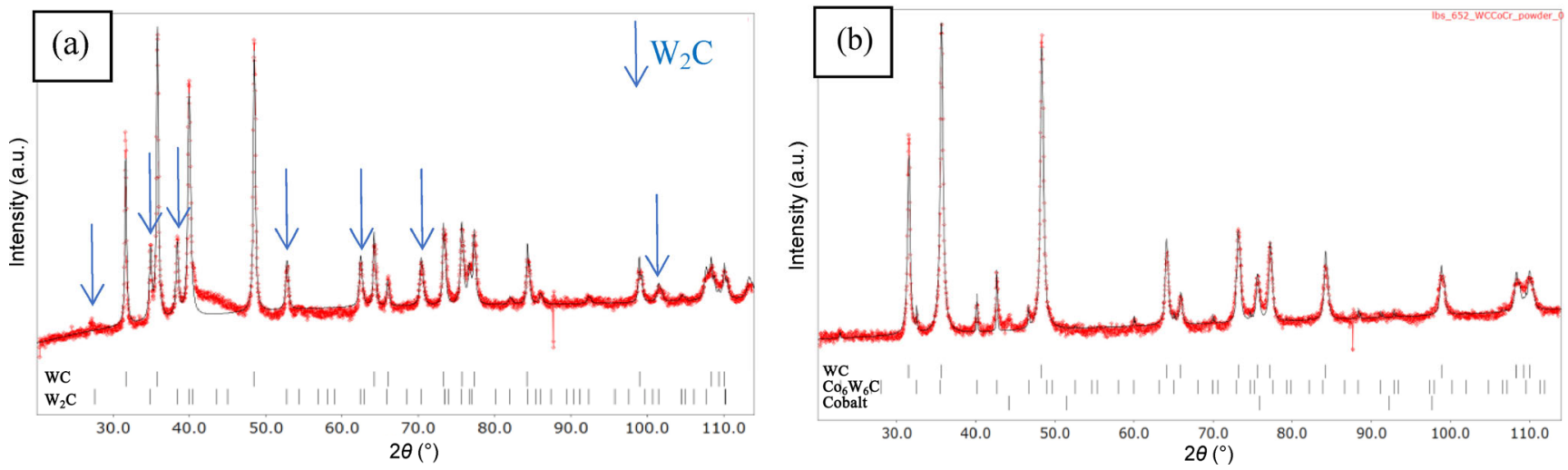

Fig. 3 (a) XRD of the HVOF coating and (b) initial powder. 
Finally, it is noteworthy that the initial powder also had a small amount of $\mathrm{Co}_{6} \mathrm{~W}_{6} \mathrm{C}(\sim 6 \mathrm{wt} \%)$, which is formed during the powder production process [21], but could not be detected in the coating; this is due to its high-temperature decarburization and subsequent dissolution into the cobalt matrix.

Wear tests were conducted using a dyno bench apparatus The test chamber was placed under a flux of air purified by an EPA filter, carrying the wear debris to a combined trapping system with two separate instruments operating in parallel to collect the emitted particles from the braking couples [22]. The first equipment was a Dekati ELPI+ impactor, which is capable of capturing and separating airborne particles, over a series of 14 stages; the particles sizes range from an average aerodynamic diameter of $10 \mu \mathrm{m}\left(\mathrm{PM}_{10}\right.$, stage 15) to $6 \mathrm{~nm}$ (stage 2). However, this study investigates only a few selected stages, particularly, the debris collected in stage 12, which corresponds to particles with an average aerodynamic diameter of $2.5 \mu \mathrm{m}$ $\left(\mathrm{PM}_{2.5}\right)$. The reason for this choice is twofold: first, $\mathrm{PM}_{2.5}$ is currently attracting increasing interest from the scientific community in view of the forthcoming standards and regulations concerning environmental policies; and second, the crystallo-chemical data of the debris collected in stage 12 of the Dekati ELPI+ were meant to tune similar data obtained with a companion PM sampling system used in this study (described herewith). Stages from 3 (=29 nm particle size) to 7 (= $255 \mathrm{~nm}$ particle size) were the additional Dekati impactor stages considered for particle analysis. Incidentally, data from particles on stage 2 (= $6 \mathrm{~nm}$ particle size) have not been considered in this study, because a preliminary survey had confirmed that the amount of ultrafine PM that reaches this (final) stage of the impactor is too small, and hence not sufficient for any reliable test. The second PM-collecting instrument was a three-stage impactor, using similar working principles as the Dekati ELPI+. Thus, in this study, the sampled particle size ranges were: (i) above $10 \mu \mathrm{m}$; (ii) between $2.5 \mu \mathrm{m}$ and $10 \mu \mathrm{m}$; and (iii) between $1.0 \mu \mathrm{m}$ and $2.5 \mu \mathrm{m}$. The second PM-collecting instrument was used to provide a larger amount of test samples than the ELPI+ impactor, which was necessary for a few additional analyses. In both instruments, however, the wear debris was stuck onto the aluminum foils, as they were sprayed with a vacuum grease.
To conduct the tests on the brake materials, two tribological couples: a pad FM4 vs. disc BD1 (codenamed FM4-BD1); and a pad FM4 vs. disc BD2 (codenamed FM4-BD2), were wear tested with the Los Angeles city traffic (LACT) cycle [23].

The collected PMs were analyzed with EDX and X-ray fluorescence (XRF) spectroscopies and SEM observations. The aluminum foils typically used for the PM-collector systems, with several spots of collected particles are shown in Fig. 4. In particular, the EDXS analyses were carried out on each disc in two spots, which are indicated as $\mathrm{E}$ (external; i.e., belonging to the external crown of the fragment spots) and $\mathrm{C}$ (central) (as shown in Fig. 4(a), only half of a collecting foil was cut out from the original one for sample preparation purposes). After peeling off the particle spots from the aluminum substrate to eliminate the X-ray emission from the substrate, XRF and EDXS analyses were performed. On each spot of the collected particles, five EDXS analyses from the fields of view containing an adequate number of debris that is representative of their relevant average composition were acquired. To compensate for the possible compositional fluctuations, the five acquisitions were evenly distributed, moving from the center towards the periphery of each spot.

XRF was performed on the particles that were still stuck on the aluminum disc for elemental mapping on a square area of $12 \mathrm{~mm} \times 12 \mathrm{~mm}$ (Fig. 4(b)). This test was conducted to verify any possible heterogeneity in the PM trapping process all over the sampling surface and in each landing spot of the particles. For a semi-quantitative XRF analysis of the debris, to be compared with the EDXS data, particle spots removed
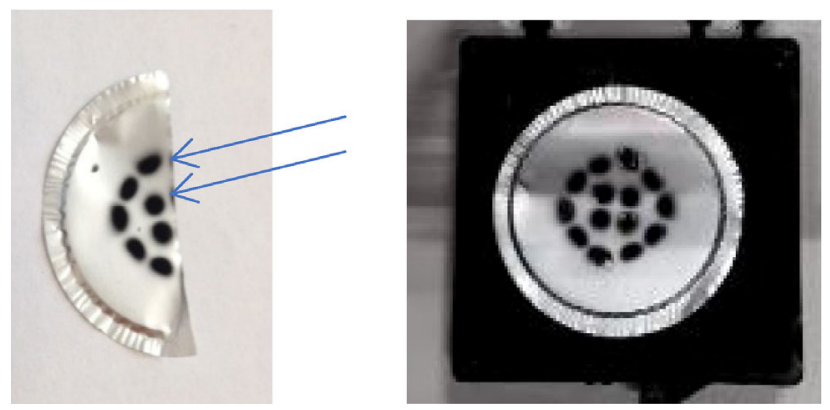

Fig. 4 Impactor Al collection plate (stage 12) with (black) spots of the collected particles. (a) Sampling procedure for EDXS analyzed spots $\mathrm{C}$ (center) and $\mathrm{E}$ (external), only half the disc is shown in the figure, (b) squared area of the XRF mapping (Fig. 5). 
from the aluminum substrate were used. The XRF measurements were performed with a Rhodium X-ray tube, under a vacuum of 20 mbar, using a voltage of $50 \mathrm{kV}$, and a current of $600 \mu \mathrm{A}$ for the map and $200 \mu \mathrm{A}$ for the spot analysis.

The finest fraction of the debris, i.e., for stages $3-5$ of the ELPI+ impactor, were analyzed using a trans mission electron microscope (TEM) equipped with an EDXS system and operated at $120 \mathrm{keV}$ accelerating voltage. The diffraction contrast images, i.e., bright and dark fields (BF and DF), were acquired in association with the selected area electron diffraction (SAED) patterns and EDX spectra of the selected regions. For the identification of the crystalline phases presented in the TEM specimens, the free Process Diffraction software was used [24]. The TEM observations required the transfer of the particles from the collecting aluminum disc onto a carbon-coated TEM gold grid, following a sample preparation procedure described elsewhere [25].

\section{Results and discussion}

\section{$3.1 \quad$ XRF}

The XRF analyses were used to estimate the qualitative composition of the wear debris and its spatial distribution on the collecting substrates, i.e., the aluminum discs sprayed with vacuum grease (see Section 2). Figure 5 shows a series of $X$-ray maps, obtained using the characteristic $X$-ray lines of some of the elements detected in the debris (FM4-BD1 dyno tests), as well as in the collecting substrates. The latter maps are in the first row in Fig. 5, showing the presence of aluminum, calcium, and zinc. The prevailing localization of these elements into the substrate is convincingly demonstrated by the contrast visible in the relevant maps, which display a more intense signal outside the areas in which the collected debris are localized. While aluminum is present in the substrate, calcium and zinc are residuals of the process control agents employed during the intense rolling procedure to produce the aluminum alloy foil. Specific XRF acquisitions carried out on the aluminum foils in the pristine pre-test conditions, also revealed the presence of iron, manganese, and titanium in minor concentrations (see relevant maps in Fig. 5).
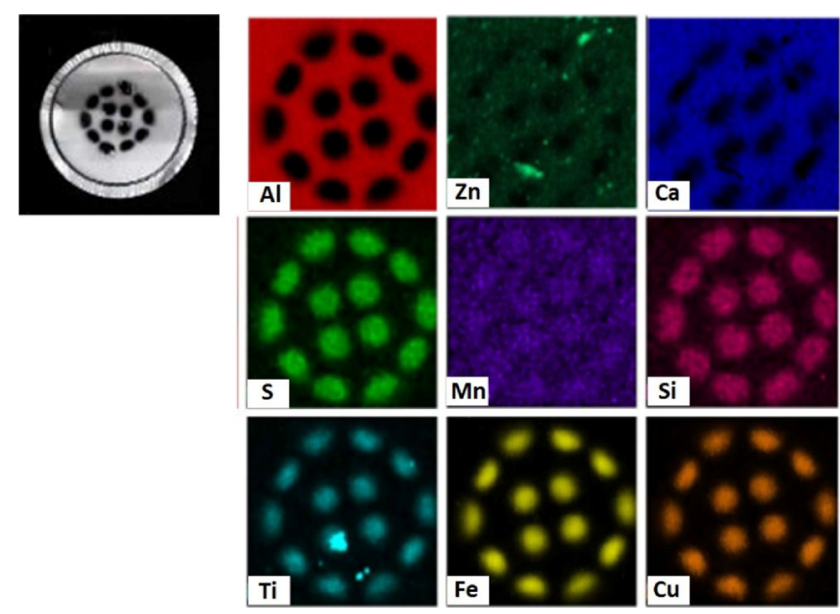

Fig. 5 XRF maps of the airborne wear particles collected on the aluminum foil of the ELPI+ impactor (stage 12), obtained from the FM4-BD1 system.

Since some of the abovementioned elements are also present in the collected debris, as suggested by the composition of the pads (Table 1) and cast iron rotor discs, any quantitative evaluation of the composition of the debris would necessarily be unreliable because of the interference between the X-Ray lines of the same elements, possibly coming from different sources. Therefore, the X-ray maps, in addition to making a qualitative estimation of the average chemical composition of the debris and substrate, effectively depict the distribution of the collected particles on the substrate.

To get rid of the substrate interference, XRF analyses on the selected particle spots (the same type of " $\mathrm{C}$ " and "E" spots used for EDXS analyses, see Fig. 4(a)) have been repeated after the spots were removed from the aluminum substrate, using an extraction replica approach as explained in Section 2, so that the selected spots of the collected particles are transferred onto an acetate substrate, emitting no detectable X-ray lines. Although a precise estimation of the absolute composition of the particles cannot be achieved considering the complexity of the effects of a finite thickness of the particle layers and the actual powder density, the XRF results (Table 3) provide the following important information: the wear debris of the FM4-BD1 system contains relatively more iron than those obtained with the FM4-BD2 system. It can therefore be concluded that the uncoated BD1 contributes significantly to the total wear of the FM4-BD1 system. This is caused by the well-established tribo-oxidation mechanisms, which 
Table 3 XRF semi-quantitative analysis of the collected particles extracted from the aluminum substrate.

\begin{tabular}{cccccccccccccccc}
\hline Pad disc & $\mathrm{O}$ & $\mathrm{Fe}$ & $\mathrm{Cu}$ & $\mathrm{Zn}$ & $\mathrm{Al}$ & $\mathrm{Ca}$ & $\mathrm{Cr}$ & $\mathrm{K}$ & $\mathrm{Mg}$ & $\mathrm{Mn}$ & $\mathrm{S}$ & $\mathrm{Si}$ & $\mathrm{Ti}$ & $\mathrm{W}$ & $\mathrm{Co}$ \\
\hline FM4+BD1 & 31.1 & 46.80 & 8.21 & 3.17 & 2.56 & 0.18 & 0.64 & 0.17 & 0.87 & 0.27 & 1.67 & 3.32 & 0.86 & - & - \\
$\mathrm{FM} 4+\mathrm{BD} 2$ & 32.3 & 19.60 & 15.50 & 5.83 & 10.28 & 0.30 & 1.74 & 0.67 & 2.88 & 0.07 & 1.90 & 4.95 & 2.90 & 0.73 & 0.22 \\
\hline
\end{tabular}

have commonly been observed and reported for such tribological couples [5, 12].

The XRD pattern in Fig. 6(a) confirms that the main phases in the FM4-BD1 debris are iron oxides, i.e., magnetite $\left(\mathrm{Fe}_{3} \mathrm{O}_{4}\right)$ and hematite $\left(\mathrm{Fe}_{2} \mathrm{O}_{3}\right)$. In addition to copper and graphite, coming from the wearing out of the pad, some diffraction lines from metallic iron are also visible in the XRD pattern, proving the occurrence of not only oxidation, but also abrasive wear and disc grinding. An important experimental detail should be underlined herewith, which is useful for a reliable interpretation of the XRD data in Fig. 6. To have a sufficient amount of powder to acquire satisfactory data, all the debris collected using the three-stage impactor was mixed to form a single specimen. This choice certainly had a diluting effect on the minor phases and/or those preferentially collected by only some of the sampling stages.

The BD2 coated disc is highly wear-resistant, as reported by Wahlström et al. [11], who tested the same friction material and disc. The specific wear rate for the FM4-BD2 couple was observed to be lower than for the FM4-BD1 couple, resulting in a lower emission rate. Consequently, the concentration of iron in the debris of FM4-BD2 is lower than that for the uncoated disc (FM4-BD1) coupling, although a certain quantity was still present, which was contributed by the FM4 pad (Table 3). Iron is mainly present in the form of magnetite $\left(\mathrm{Fe}_{3} \mathrm{O}_{4}\right)$ and to a lower extent as metallic

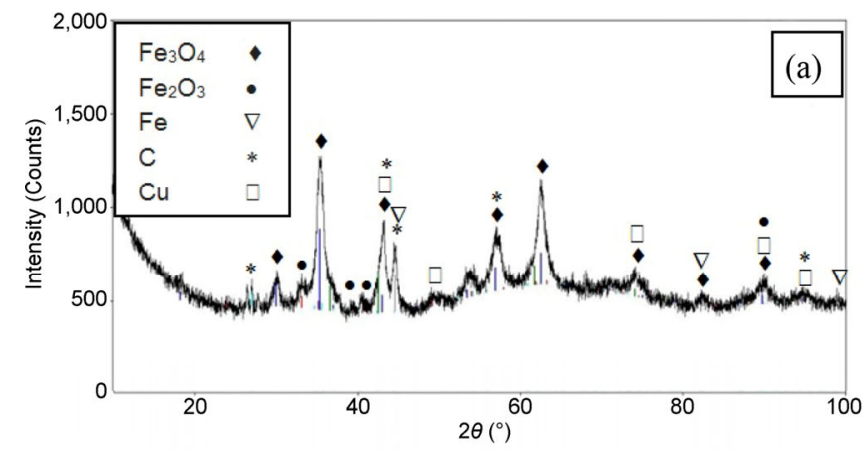

Fig. 6 XRD of airborne debris of (a) FM4-BD1 and (b) FM4-BD2 systems.

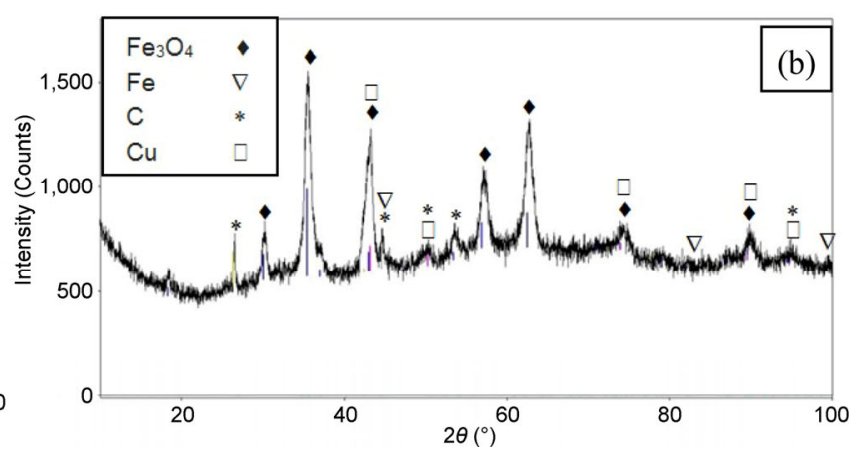

iron (Fig. 6(b)). In association with the coated BD2 disc, the brake pad exhibits a comparatively higher wear rate [13], as proved by the initial higher concentrations in the wear debris of all components of the pad, namely copper, silicon, and aluminum (compare Tables 1 and 3 ). Moreover, it is important to note that although the presence of cobalt and tungsten is limited in the wear debris, as measured via XRF, the hard coating is subjected to wear during the tests.

\subsection{SEM-EDXS}

Particles from the FM4-BD1 system, collected on the ELPI+ stage 12 are shown in Fig. 7(a). Their average size confirms the nominal sensitivity of this stage of the PM-collecting instrument to particles with an average diameter of $2.5 \mu \mathrm{m}$. From five of these fields of view, as described in the Section 2, the EDXS spectra have been acquired for a few particle spots on the stage $n: 12$ of the ELPI+ impactor (Fig. 4(a)), moving from the center toward the periphery. The results obtained for one of the analyzed particle spots are presented in a graphical form in Fig. 8.

The same analysis was performed on the debris from the FM4-BD2 system dyno tests (Fig. 7(b)) and all data have been summarized in Table 4. A comparative evaluation of the data in Tables 3 and 4 indicates that, irrespective of the unavoidable differences in the absolute concentration values measured with the two spectroscopies, i.e., XRF and EDXS, similar comments 

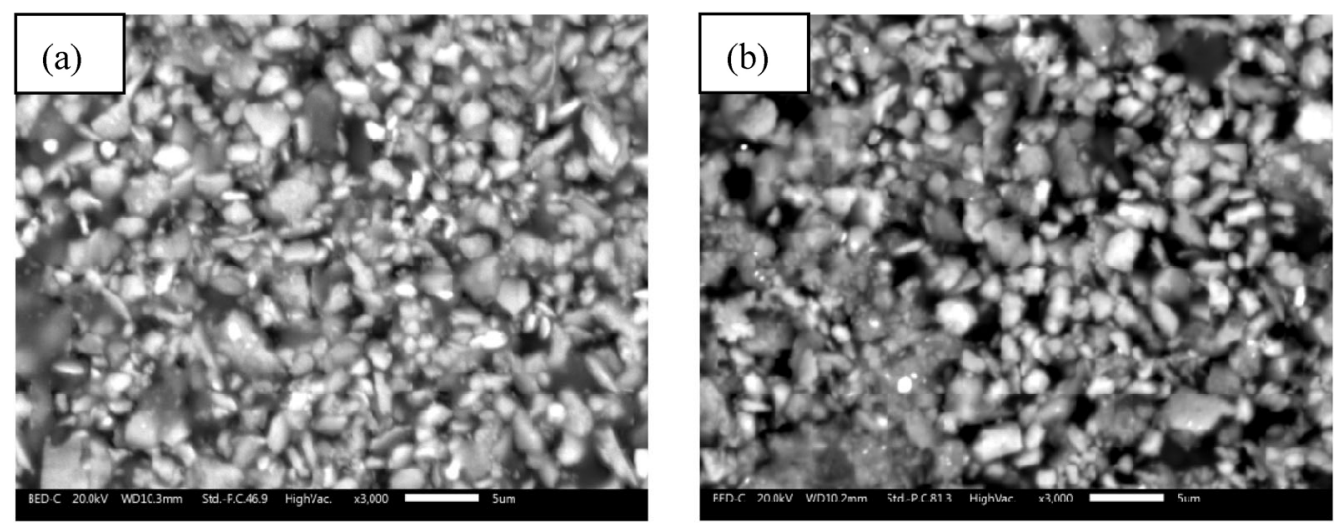

Fig. 7 SEM micrographs of fragments collected by the ELPI+ impactor (stage 12) from (a) FM4-BD1 and (b) FM4-BD2 systems.
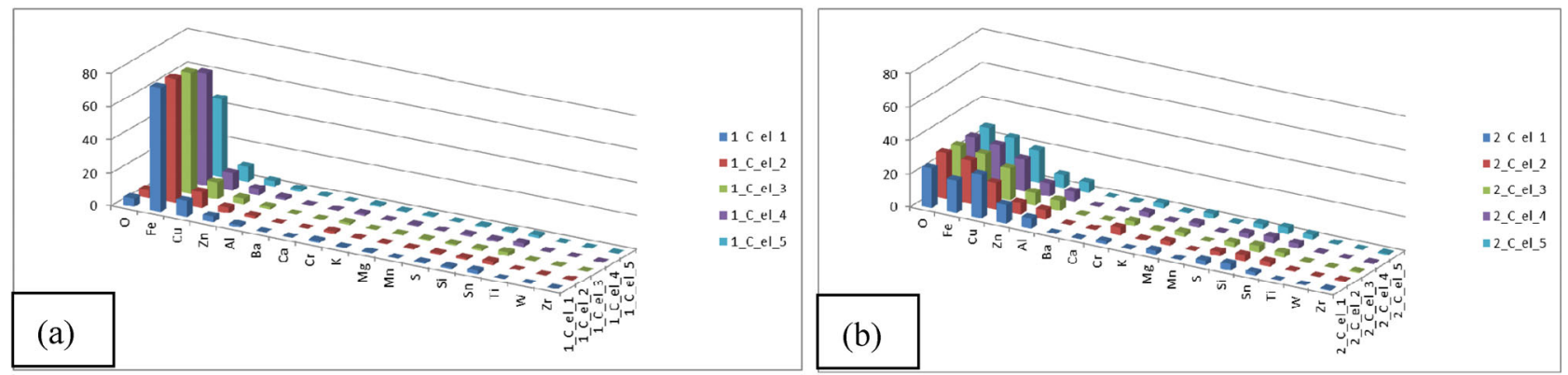

Fig. 8 Results of the five EDXS analyses carried out on spot C of the filter ELPI+ stage 12 from (a) FM4-BD1 and (b) FM4-BD2 systems.

Table 4 EDXS results of fragments collected, average value between spots C and E (Fig. 4(a)) of each pad+disc couple.

\begin{tabular}{ccccccccccccccccc}
\hline Pad disc & $\mathrm{O}$ & $\mathrm{Fe}$ & \multicolumn{1}{c}{$\mathrm{Cu}$} & $\mathrm{Zn}$ & $\mathrm{Al}$ & $\mathrm{Ca}$ & $\mathrm{Cr}$ & $\mathrm{K}$ & $\mathrm{Mg}$ & $\mathrm{Mn}$ & $\mathrm{S}$ & $\mathrm{Si}$ & $\mathrm{Sn}$ & $\mathrm{Ti}$ & $\mathrm{W}$ & $\mathrm{Co}$ \\
\hline FM4+BD1 & 27.94 & 53.03 & 6.16 & 2.29 & 2.45 & 0.20 & 0.76 & 0.18 & 0.86 & 0.33 & 0.97 & 1.98 & 1.82 & 0.97 & - & - \\
$\mathrm{FM}+\mathrm{BD} 2$ & 22.97 & 25.17 & 21.07 & 7.75 & 4.32 & 0.25 & 1.91 & 0.52 & 1.43 & 0.22 & 2.49 & 1.79 & 4.37 & 2.58 & 3.24 & 0.26 \\
\hline
\end{tabular}

can still be proposed on the relative values.

In particular, it is confirmed that when the pad is tested against the uncoated disc (BD1), iron (in the form of oxides) is the main constituent of the wear debris, owing to the dominant tribo-oxidation of the cast iron disc [5-9]. On the other hand, tests against the coated disc show that the wear products mainly comprise pad components, including iron as iron oxides, according to the XRD data (Fig. 6(b)).

Furthermore, electron microscopy observations have also been used to analyze the PM from the wear of the coated disc. As already observed in the XRF and confirmed by EDXS results, the presence of tungsten and cobalt in the wear debris indicates that, even if the total amount of PM produced in this case is much lower than that produced with the uncoated cast iron disc, there still exists disc wear to some extent. Considering that the original carbide average grain size falls in the range of a few micrometers (Fig. 2(b)), it was decided to conduct a systematic survey on the debris collected by the stage operating on the $1.0 \mu \mathrm{m}-$ $2.5 \mu \mathrm{m}$ size range of particles using the three-stage impactor. In this way, a wider statistics of the sizes of the released carbides can potentially be sampled. The particles thus collected are shown in Fig. 9(a). The debris appear clustered in agglomerates of several tens of micrometers. As already reported in former studies $[5,6,14,26]$, this is uncommon situation is caused by the combined effect of magnetic attraction, which is due to the presence of magnetite in the debris, and surface energy reduction, which also involves possible electrostatic interactions [27].

A high-magnification X-Ray map collected on the same field of view as that in Fig. 9(a) reveals that tungsten is concentrated in small brighter particles (marked by arrows in Fig. 9(b)). These particles exhibit 

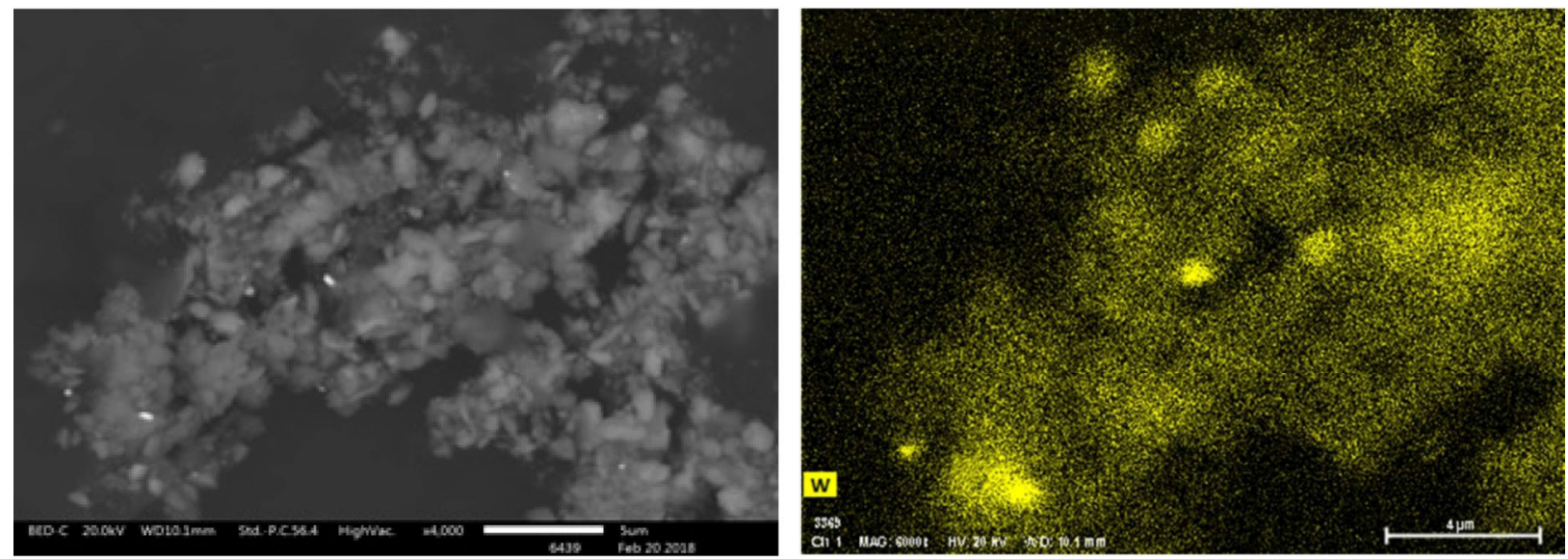

Fig. 9 (a) Cluster of wear debris collected by the $1.0 \mu \mathrm{m}-2.5 \mu \mathrm{m}$ stage of the three-stage impactor, (b) EDXS X-ray map for tungsten, collected on the same field of view as in Fig. 9(a), showing the higher concentration of this element in correspondence of the brighter fragment marked by arrows in the SEM image in Fig. 9(a).

an average size and morphology comparable to those of the carbides that are still present in the coating (Fig. 2(b)). These observations indicate that a detachment of unfragmented carbide particles from the metallic matrix of the coating occurs during the wear tests. In agreement with these observations, no carbide particles were detected in the collected wear particles of average grain size below $1 \mu \mathrm{m}$. This detachment dynamics of carbide particles from the metallic matrix would be coherent with the low or nil cobalt in association with these particles, as confirmed by pin-pointed EDXS analyses. Therefore, an obvious amelioration to the coating durability might be attained through the enhancement of the carbide adhesion strength to the cobalt matrix [28].

To complete the characterization of the airborne wear particles of the FM4-BD2 system, TEM analyses were performed on the finer fractions of the collected PM, referring to stages 3-5 (particle size: $29 \mathrm{~nm}-94 \mathrm{~nm}$ ) of the ELPI+ impactor. The PM having an average aerodynamic diameter below $1 \mu \mathrm{m}$, known as the ultrafine particulate (UFP) and is currently attracting growing research interest [29], which might probably lead to the implementation of relevant public policies and regulations shortly. In this context, higher resolution observations and analyses would be very effective in completing and confirming the wear mechanism picture, as apparent from the results presented in the previous sections, particularly with regard to the coated disc system.

The TEM micrograph and relevant EDXS analyses in Fig. 10 show iron-based debris, exhibiting two
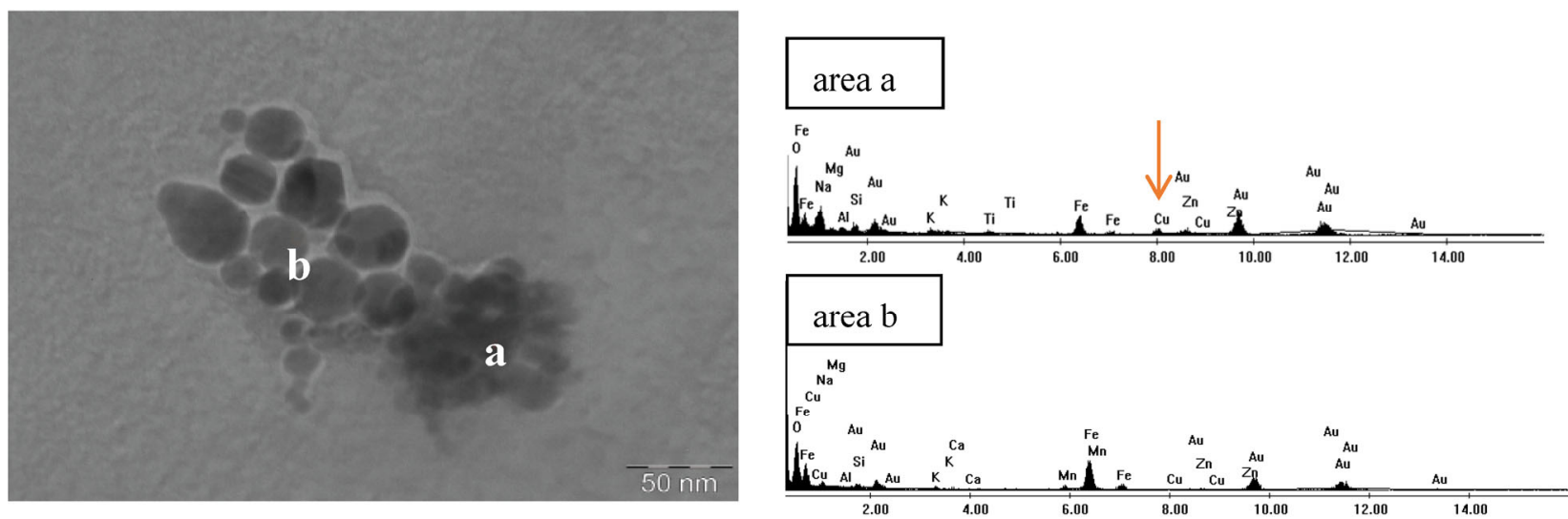

Fig. 10 TEM micrograph and relevant EDX spectra on iron containing debris collected by the stage 5 (average diameter of collected particles: $94 \mathrm{~nm}$ ) of ELPI+, during dyno testing of the sample FM4-BD2. The Au characteristic lines are due to the gold grids used for TEM specimen preparation. 
different microstructures and compositions.

The region "a", as observed from the corresponding EDX spectrum, is mainly composed of fine grains of magnetite intermixed and held together by nanocrystalline copper, according to a notorious scheme $[22,30]$. They come from the abrasion of the iron fibers presented in the FM4 pad (Fig. 1) and before being ejected from the tribological system, undergo a sort of rolling-grinding deformation while remaining trapped in between the two mating surfaces of the pads and the coated disc. Moreover, it is noteworthy that the presence of the BD2 hard coating on the disc surface enhances the grinding effect. This composition also confirms the XRD data (Fig. 6(b)) with reference to the finer fraction of the wear particles. The TEM observations further revealed the expected presence of other pad components in the ultrafine fraction of the wear debris, such as $\mathrm{TiO}_{2}$ (Fig. 11) and kaolinite (Fig. 12).
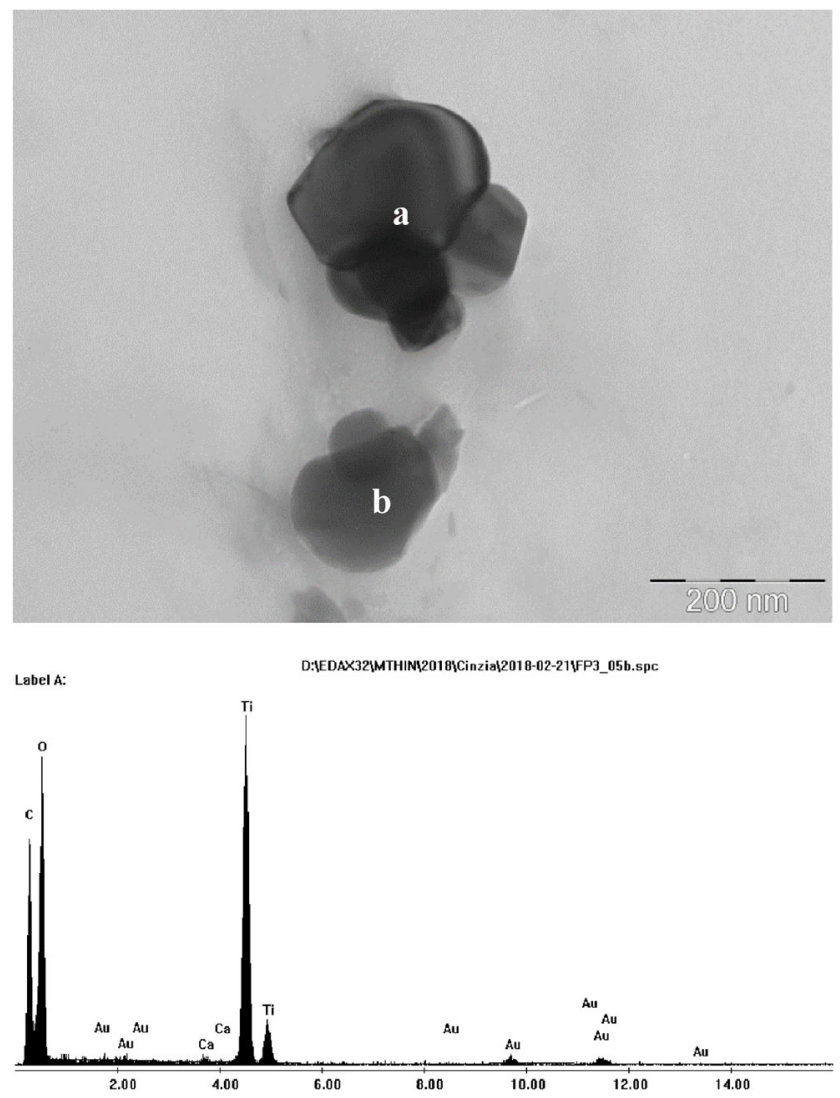

Fig. 11 TEM micrograph of $\mathrm{TiO}_{2}$ particles detected on filter stage 3 (average diameter of collected particles: $29 \mathrm{~nm}$ ) and identified from the relevant EDX spectrum (same for particles in both (a) and (b)), showing the presence of oxygen and titanium characteristic X-ray lines.

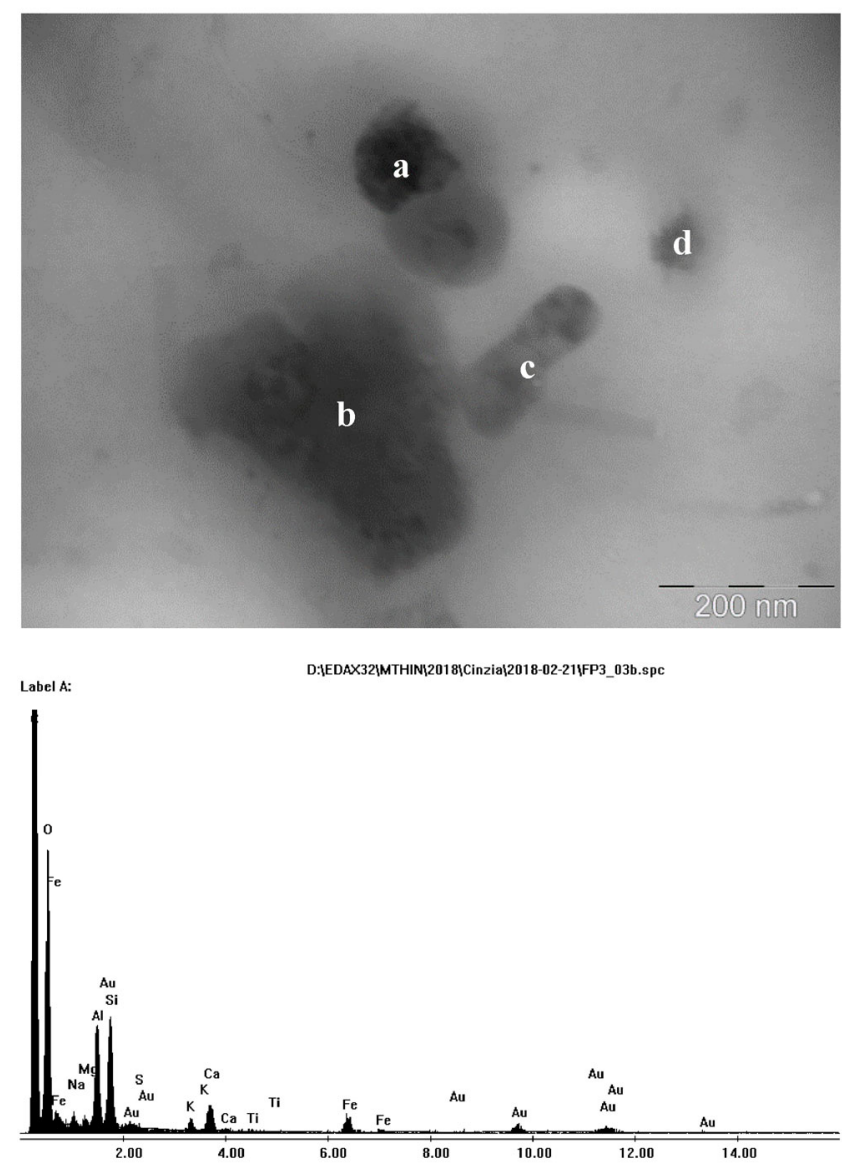

Fig. 12 TEM micrograph showing ultra-fine kaolinite grains, a component of the FM4 pad material, detected on filter stage 3 (average diameter of collected particles: $29 \mathrm{~nm}$ ). A similar spectrum was found in the other four-analyzed spots (a, b, c, and d).

\section{Conclusions}

The development of novel materials for vehicular brake systems is currently driven not only by the need for better performance and durability, but also a more environmentally friendly behavior, particularly concerning emissions. To validate the new technological choices, reliable material characterization protocols are required; i.e., to confirm that the presumed improvements are truly genuine, even as concerns aspects not yet in the standards or legislation but still important for the public health. This study conducted an indepth characterization of the wear debris produced by a low-met brake pad (FM4), which was dynobench tested against an uncoated cast iron (BD1) and a WC-CoCr HVOF-coated (BD2) disc. A broad range (30 $\mathrm{nm}$ to $10 \mu \mathrm{m}$ ) of emitted airborne PM size range was considered, which required the adoption of a 
multi-analytical characterization approach using several experimental techniques and relevant sample preparation procedures.

The main results emerging from this investigation can be summarized as follows:

(1) In the tests involving both coated (BD2) and uncoated (BD1) discs, the main wear products are observed to be iron oxides, mostly magnetite. However, since the wear-resistant coating does not contain iron, in the FM4-BD2 tribological system, the oxidation involves only the iron fibers that are present in the friction material.

(2) The analyses of the finer fractions of the wear debris show additional components in the wear products, from which, although beyond the scope of the present research, the following main wear mechanisms can be inferred: FM4-BD1: mainly tribo-oxidation, involving both disc and pad materials; FM4-BD2: abrasion and tribo-oxidation, involving the pad material only.

(3) However, some tungsten carbides have been detected in the wear debris, proving that a limited wearing out of the coating has also occurred. Moreover, the microstructural features of the carbides indicate that the main detachment mechanism is the tearing off of the hard particles, with no significant fragmentation. Indeed, the carbides in the collected particles exhibit the same size and morphology they have in the coating.

Thus, the results of this investigation provide possible strategies that may be pursued to improve the braking performances and the emission behavior of the newly developed materials; this is one of the main tasks of the H2020 EU project: LOWBRASYS, i.e., a LOW environmental impact BRAke SYStem, within which the present research has been conducted.

\section{Acknowledgements}

The authors would like to thank their colleague Gloria Ischia, Ph.D, for her valuable technical assistance for the TEM sample preparation and observations. Our colleague, friend, and project leader, Guido Perricone (Brembo S.p.A.) is also acknowledged for his continuous encouragement in pursuing our goals while working together within the H2020 EU Project:
LOWBRASYS - a LOW environmental impact BRAke SYStem-GA: 636592. The EU Commission is acknowledged for its financial support.

Open Access This article is licensed under a Creative Commons Attribution 4.0 International License, which permits use, sharing, adaptation, distribution and reproduction in any medium or format, as long as you give appropriate credit to the original author(s) and the source, provide a link to the Creative Commons licence, and indicate if changes were made.

The images or other third party material in this article are included in the article's Creative Commons licence, unless indicated otherwise in a credit line to the material. If material is not included in the article's Creative Commons licence and your intended use is not permitted by statutory regulation or exceeds the permitted use, you will need to obtain permission directly from the copyright holder.

To view a copy of this licence, visit http://creativecommons.org/licenses/by/4.0/.

\section{References}

[1] Grigoratos T, Martini G. Brake wear particle emissions: A review. Environ Sci Pollut Res 22(4): 2491-2504 (2015)

[2] Harrison R M, Jones A M, Gietl J, Yin J X, Green D C. Estimation of the contributions of brake dust, tire wear, and resuspension to nonexhaust traffic particles derived from atmospheric measurements. Environ Sci Technol 46(12): 6523-6529 (2012)

[3] Straffelini G, Ciudin R, Ciotti A, Gialanella S. Present knowledge and perspectives on the role of copper in brake materials and related environmental issues: A critical assessment. Environ Pollut 207: 211-219 (2015)

[4] Policandriotes T, Filip P. Effects of selected nanoadditives on the friction and wear performance of carbon-carbon aircraft brake composites. Wear 271(9-10): 2280-2289 (2011)

[5] Verma P C, Menapace L, Bonfanti A, Ciudin R, Gialanella S, Straffelini G. Braking pad-disc system: Wear mechanisms and formation of wear fragments. Wear 322-323: 251-258 (2015)

[6] Verma P C, Alemani M, Gialanella S, Lutterotti L, Olofsson U, Straffelini G. Wear debris from brake system materials: A multi-analytical characterization approach. Tribol Int 94: 249-259 (2016)

[7] Hinrichs R, Vasconcellos M A Z, Österle W, Prietzel C. A 
TEM Snapshot of magnetite formation in brakes: The role of the disc's cast iron graphite lamellae in third body formation. Wear 270(5-6): 365-370 (2011)

[8] Österle W, Dörfel I, Prietzel C, Rooch H, Cristol-Bulthé A L, Degallaix G, Desplanques Y. A comprehensive microscopic study of third body formation at the interface between a brake pad and brake disc during the final stage of a pin-on-disc test. Wear 267(5-8): 781-788 (2009)

[9] Wahlström J, Olander L, Olofsson U. Size, shape, and elemental composition of airborne wear particles from disc brake materials. Tribol Lett 38(1): 15-24 (2010)

[10] Grabiec T. Wear and friction behavior of friction pairs tested with different types of grey cast iron and low met friction material. SAE Int J Passeng Cars-Mech Syst 7(4): 1361-1368 (2014)

[11] Wahlström J, Lyu Y, Matjeka V, Söderberg A. A pin-ondisc tribometer study of disc brake contact pairs with respect to wear and airborne particle emissions. Wear 384-385: 124 130 (2017)

[12] Straffelini G, Verma P C, Metinoz I, Ciudin R, Perricone G, Gialanella S. Wear behavior of a low metallic friction material dry sliding against a cast iron disc: Role of the heat-treatment of the disc. Wear 348-349: 10-16 (2016)

[13] Federici M, Menapace C, Moscatelli A, Gialanella S, Straffelini G. Pin-on-disc study of a friction material dry sliding against HVOF coated discs at room temperature and $300{ }^{\circ}$ C. Tribol Int 115: 89-99 (2017)

[14] Mosleh M, Blau P J, Dumitrescu D. Characteristics and morphology of wear particles from laboratory testing of disk brake materials. Wear 256(11-12): 1128-1134 (2004)

[15] Kukutschová J, Moravec P, Tomášek V, Matějka V, Smolík J, Schwarz J, Seidlerová J, Šafářová K, Filip P. On airborne nano/micro-sized wear particles released from low-metallic automotive brakes. Environ Pollut 159(4): 998-1006 (2011)

[16] Gietl J K, Lawrence R, Thorpe A J, Harrison R M. Identification of brake wear particles and derivation of a quantitative tracer for brake dust at a major road. Atmos Environ 44(2): 141-146 (2010)

[17] Wahlström J, Söderberg A, Olander L, Jansson A, Olofsson U. A pin-on-disc simulation of airborne wear particles from disc brakes. Wear 268(5-6): 763-769 (2010)

[18] Lutterotti L, Matthies S, Wenk H R, Schultz A S, Richardson J W Jr. Combined texture and structure analysis of deformed limestone from time-of-flight neutron diffraction spectra. J Appl Phys 81(2): 594 (1997)
[19] Rietveld H M. A profile refinement method for nuclear and magnetic structures. J Appl Cryst 2(2): 65-71 (1969)

[20] Yuan J H, Zhan Q, Huang J, Ding S Y, Li H. Decarburization mechanisms of WC-Co during thermal spraying: Insights from controlled carbon loss and microstructure characterization. Mater Chem Phys 142(1): 165-171 (2013)

[21] Verdon C, Karimi A, Martin J L. A study of high velocity oxyfuel thermally sprayed tungsten carbide based coatings. Part 1: Microstructures. Mater Sci Eng A 246(1-2): 11-24 (1998)

[22] Perricone G, Matějka V, Alemani M, Valota G, Bonfanti A, Ciotti A, Olofsson U, Söderberg A, Wahlström J, Nosko O, et al. A concept for reducing $\mathrm{PM}_{10}$ emissions for car brakes by 50\%. Wear 396-397: 135-145 (2018)

[23] Perricone G, Alemani M, Metinöz I, Matějka V, Wahlström J, Olofsson U. Towards the ranking of airborne particle emissions from car brakes - a system approach. Proc Inst Mech Eng, Part D: J Automob Eng 231(6): 781-797 (2017)

[24] Lábár J L. Consistent indexing of a (set of) SAED pattern(s) with the Process Diffraction program. Ultramicroscopy 103(3): 237-249 (2005)

[25] Gialanella S, Ischia G, Maines L, Straffelini G. A sample preparation protocol for electron microscopy investigations of filter collected ultrafine environmental particles, to be submitted to Ultramicroscopy (2019)

[26] Kukutschová J, Roubíček V, Malachová K, Pavlíčková Z, Holuša R, Kubačková J, Mička V, MacCrimmon D, Filip P. Wear mechanism in automotive brake materials, wear debris and its potential environmental impact. Wear 267(5-8): 807-817 (2009)

[27] Hotze E M, Phenrat T, Lowry G V. Nanoparticle aggregation: Challenges to understanding transport and reactivity in the environment. J Environ Qual 39(6): 1909-1924 (2010)

[28] Konyashin I, Zaitsev A A, Sidorenko D, Levashov E A, Ries B, Konischev S N, Sorokin M, Mazilkin A A, Herrmann M, Kaiser A. Wettability of tungsten carbide by liquid binders in WC-Co cemented carbides: Is it complete for all carbon contents? Int $J$ Ref Metals Hard Mat 62: 134-148 (2017)

[29] Kumar P, Pirjola L, Ketzel M, Harrison R M. Nanoparticle emissions from 11 non-vehicle exhaust sources - a review. Atmos Environ 67: 252-277 (2013)

[30] Österle W, Prietzel C, Kloß H, Dmitriev A I. On the role of copper in brake friction materials. Tribol Int 43: 2317-2326 (2010) 


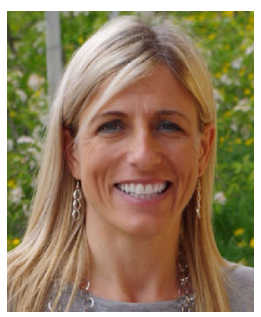

Cinzia MENAPACE. She graduated from materials engineering at the University of Trento in 1999. She received Ph.D degree in metallurgical engineering from the University of Padova (Italy) in 2003.

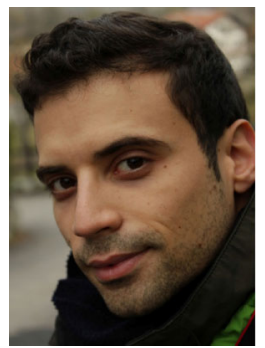

Alessandro MANCINI. He obtained his Ph.D in chemistry at the University of Pavia in 2015, after completing bachelor and master degrees in the same university. Following Ph.D period, he joined

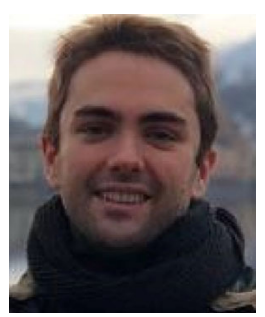

Matteo FEDERICI. He is currently undertaking doctoral studies at the University of Trento, Italy. His Ph.D project aims at developing and testing new materials for braking systems able to reduce the par-

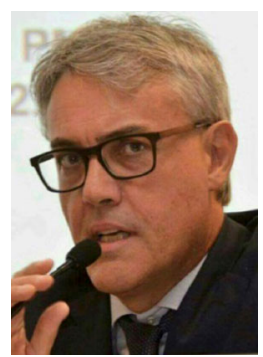

Giovanni STRAFFELINI. He received his master degree in materials science and engineering from the University of Trento, Italy, in 1989, and his Ph.D in metallurgical engineering from the University of Padova in 1993. He is currently a

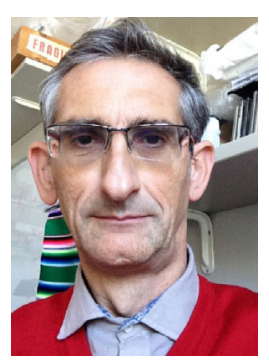

Stefano GIALANELLA. He is an associate professor in materials science and technology. His more recent research interests concern: phase transformations, high temperature oxidation and wear of structural alloys and materials for
She has been working as a junior and senior researcher at the University of Trento for 20 years. Her current position is the research assistant of metallurgy at University of Trento (Italy). Her research interests include the powder metallurgy, friction materials, and hot workability of metals.

Brembo as a research scientist in the Advance $R \& D$ Department. His main activities focus on solid material characterization, in particular by means of X-ray techniques such as X-Ray Diffraction, Fluorescence, and Computed Tomography.

ticulate matter emissions due to the wear of the brake components. His research interests include the study of the frictional, wear behavior of HVOF-sprayed coatings, and friction materials for automotive and aerospace applications.

full professor in metallurgy at the University of Trento. His research interests include the mechanical properties of sintered alloys and weldments, the tribological behavior of materials, including friction materials for automotive and aerospace brakes, the properties of surface engineered surfaces.

brake systems, nanostructured materials, their microscopy characterisation, archaeometry, and cultural heritage issues. On these and related subjects, he teaches courses for undergraduate and graduate students of the Departments of Industrial Engineering and of Humanities of the University of Trento, Italy. 